\title{
Web-Based Decision Support Framework for Water Resources Management at River Basin Scale
}

\author{
José Pinho, José Vieira, \\ Rui Pinho and José Araújo \\ Department of Civil Engineering, University of Minho
}

Portugal

\section{Introduction}

In recent years a major effort has been done to make water quality modelling tools available for water resources management at a river basin scale. The European water framework directive clear states that these tools must be used in making the diagnostic of surface water bodies water quality status and to anticipate the impact of measures to be implemented in order to achieve a good ecological status by 2015 in European waters (European Commission 2000; Rekolainen 2003; Horn et al. 2004; Ravesteijn \& Kroesen 2007; Volk et al. 2008).

In order to make modelling tools usable by all the actors enrolled in water resources management process at river basins, these tools must be simple, user-friendly and robust. Water managers have shown strong interest in the integration of model tools throughout the use of graphical interfaces in their activities (Borowski \& Hare 2007). These tools must be able to establish water management scenarios but it is well known that water managers have lack of time for training in the use of complex systems. Also software and hardware costs appear to be an important constrain in implementing these tools.

Several solutions are being implemented throughout European countries, resulting from the development and integration of different software packages using different integration technologies (Dudley et al. 2005, Berlekamp et al. 2007, De Kok et al. 2009).

This chapter presents a hydroinformatic environment (Price, 2000) specifically designed for a Portuguese north-western river basin (river Cávado) in order to define, simulate and analyse hydrodynamics and water quality management scenarios - the ODeCav System. The software solution was designed to be operated in a web environment, taking advantage of the integration capabilities of this software environment and the user friendliness of web interfaces. It is composed of the following main components: water monitoring data-bases, hydrodynamics and water quality river models, and reports facilities for the presentation of output results. The applicability of this hydroinformatic environment is exposed in the study of waste water treatment plants (WWTP) discharges impacts on the river water quality for different river flow regimes. 


\section{Methods}

\subsection{Water quality models}

The flow is modeled using one-dimensional formulations of free surface flows based on the conservation of mass and momentum equations:

$$
\begin{gathered}
\frac{\partial A_{f}}{\partial t}+\frac{\partial Q}{\partial x}=q_{\text {lat }} \\
\frac{\partial \boldsymbol{Q}}{\partial t}+\frac{\partial}{\partial x}\left(\frac{\boldsymbol{Q}^{2}}{A_{f}}\right)+g A_{f} \frac{\partial h}{\partial x}+\frac{g Q|Q|}{C^{2} R A_{f}}-W_{f} \frac{\tau_{w i}}{\rho_{w}}=0
\end{gathered}
$$

where,

Q Water flow discharge in $\mathrm{m}^{3 /} \mathrm{s}$;

$\mathrm{t} \quad$ Time in s;

$\mathrm{x} \quad$ Distance in $\mathrm{m}$;

$\mathrm{A}_{\mathrm{f}} \quad$ Wetted area in $\mathrm{m}^{2}$;

qlat Lateral flow discharge in $\mathrm{m}^{2} / \mathrm{s}$;

g Gravity acceleration in $\mathrm{m} / \mathrm{s}^{2}$;

$\mathrm{h} \quad$ Water depth in $\mathrm{m}$;

C Chezy coefficient in $\mathrm{m}^{1 / 2 / \mathrm{s}}$;

$\mathrm{R} \quad$ Hydraulic radius in $\mathrm{m}$;

$\mathrm{W}_{\mathrm{f}} \quad$ Flow width in $\mathrm{m}$;

$\tau_{\mathrm{wi}} \quad$ Wind shear stress in $\mathrm{N} / \mathrm{m}^{2}$;

$\rho_{\mathrm{w}} \quad$ Water density in $\mathrm{kg} / \mathrm{m}^{3}$.

In addition to these equations the flow discharges at hydraulic structures included in the model segmentation are computed using specific expressions for each type of structure: bridges, culverts, siphons, orifices, pumps, and weirs. In these structures the flow depends on the upstream and downstream levels, on its dimensions and on a set of specific parameters.

The water quality model is based on the one-dimensional transport equation:

$$
\frac{\partial\left(A_{f} C\right)}{\partial t}=-\frac{\partial(Q C)}{\partial x}+\frac{\partial}{\partial x}\left(D A_{f} \frac{\partial C}{\partial x}\right)+S A_{f}
$$

where,

C Substance concentration in $\mathrm{kg} / \mathrm{m}^{3}$;

D Diffusion coefficient in $\mathrm{m}^{2} / \mathrm{s}$;

$\mathrm{S} \quad$ Source, sink and reaction term in $\mathrm{kg} / \mathrm{m}^{3 /} \mathrm{s}$.

The last term of Eq. 3 refers to the sources and sinks and the dependence on the processes occurring in the water column related with the modeled substance. For each water quality problem a set of equations are considered, one for each substance involved in the water quality problem to simulate. The different biogeochemical processes relevant to the study of surface water quality problems have a great diversity. In this work it was chosen a processes 
framework, as much inclusive as possible that cover simple water quality processes, such as the modeling of accidental releases of conservative pollutants, or more complex processes, such as degradation of organic matter.

For problems involving conservative substances it is only considered the transport of the substance in the water through advection and diffusion. The evaluation of the extensions and durations of accidental discharge can be carried out recurring to a model in which the accidental discharge is modeled by a conservative substance. In addition to the cases of accidental discharge, these simple models also have practical interest to quantify the residence times and to analyze the effect of different hydrodynamic conditions in the water masses mixing conditions.

The majority of elements and substances in aquatic environments have reactions with other elements and/ or substances, resulting in their transformation (decrease or increase in concentration). Bacterial contamination arising from discharges of domestic wastewater or diffuse sources, for example, can be modeled by taking up a 1st-order decay law. The behavior of many other substances (or species) can be approximated by considering the decay or grow th of a second order, such as biochemical oxygen demand (BOD) or algae. The reaction coefficients should be established mainly through the available field data or laboratory tests. Dissolved oxygen (DO) is a common environmental element used to characterize the water quality in water systems. The analysis of the impact caused by discharges with a high concentration of organic matter may be made to quantify the effects in terms of variations in concentrations of dissolved oxygen in the water column, due to the decomposition of organic matter contained in wastewater discharges. The water quality processes library used in this work is one of the most complete for surface water quality modeling and includes all the relevant processes allowing the establishment of either complex water quality processes or simple ones depending on data availability.

\subsection{Web-based hydroinformatic environment}

The developed technological platform is mainly based on a database system and a set of hydrological, hydrodynamic and water quality models, operated using web interfaces. It comprises functionalities for query and analysis of the river network (information system), hydrodynamic and water quality models operation (modelling system), and results analysis (analysis system). Besides this, the platform provides the following additional services: user's management, document management and monitoring data store and display. The user's management service allows restricting or not the access to various content, as well as the permissions to run/ execute or to view/ consult/ query the simulations results. The document management service allows the users to perform simple tasks, such as publication of papers and upload/ download of work documents. The monitoring data functionalities provides a framework for gauge and water quality stations installed in the river basin, allowing its analysis, validation, and integration using a specifically designed database for this purpose.

The website responsible for the system interaction with the end users is divided into four main sections that allow access to the features mentioned above: Project, Information, Modelling and Analysis. These sub-menus are the main options from the navigation menu (Figure 1). 


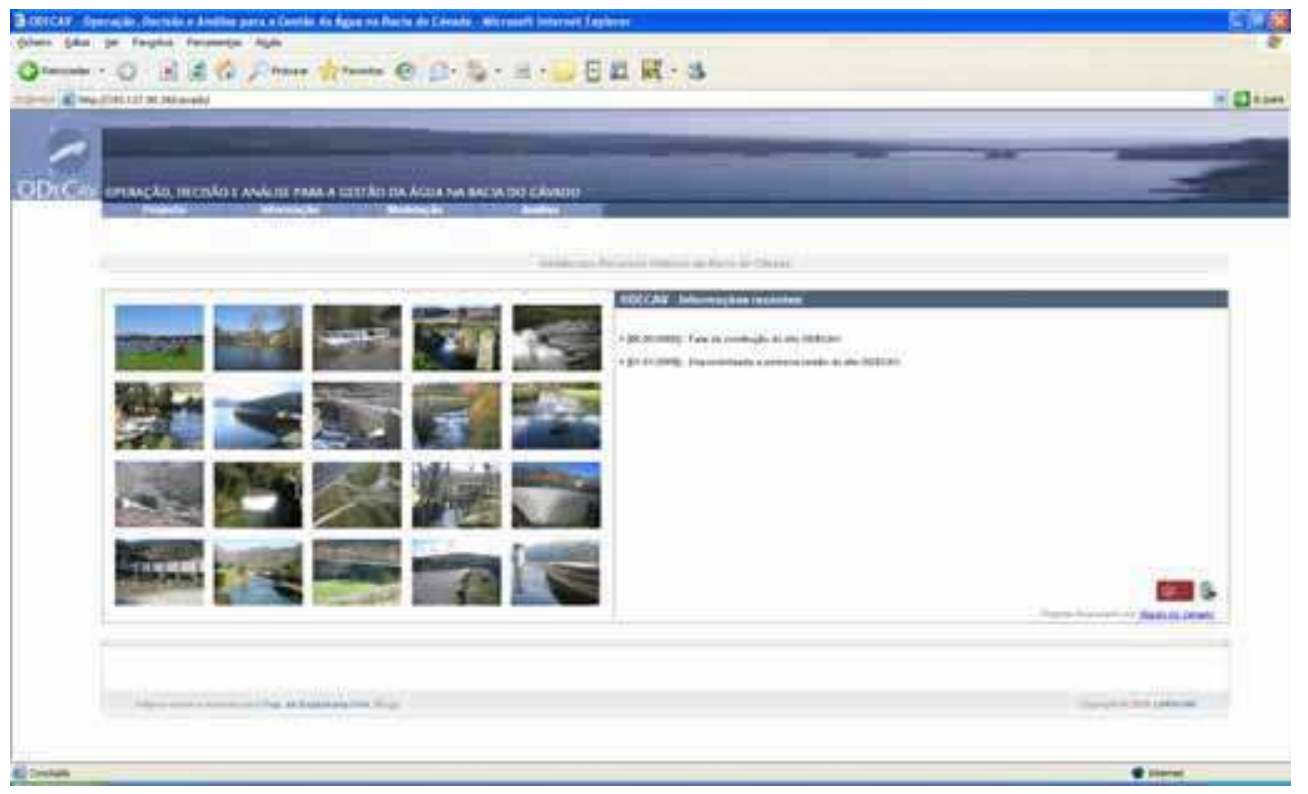

Fig. 1. Main window of the ODeCav modelling system

Implemented data-bases store geometric features of the river network, hydraulic structures, monitoring stations data, and point and non-point pollutant discharges into the river network. This was done using MySQL server (MYSQL 2009). The one-dimensional hydrodynamics and water quality models were implemented applying SOBEK software that numerically solves Eq. 1 to 3 . This is commercial softw are developed and maintained by DELTARES (2009). Specific web-based model operation interfaces were developed in order to directly establish the simulation boundary conditions, run the model and visualize model results. All the developed applications are freely available since it will be used for research purposes.

The Project section presents information about the aim of the developed platform and its main characteristics. It also gives access to the document management tool. In the Information section it is possible to query the geographical database of the river basin. It includes information about details of the river network, data from monitoring stations and the river basin Geographic Information System. The Modelling section allows the users to define new simulations and remotely start the execution of the hydrodynamic and water quality models. This application not only allows the remote operation of the models, but also displays the simulation results from different users. Finally, the Analysis section provides access to several simulation results for a posterior detailed analysis and generation of reports. Each one of these sections includes graphical user interfaces, specifically designed and developed for that purpose, considering imposed requisites of its potential users.

Most of the content of the website has conditioned/ restricted access. This means that it is available only through user authentication. A user without a valid login can only view/ access the information provided under the Project menu (Figure 1). Any user who 
was granted with permissions (which has a user registration and password) will have access to the full content of the interface. However, this does not mean the user has permission to view, use or access all the features, functionalities and tools available in the interface. There are interfaces that differentiate the privileges of users. For example, while some users may start the execution of the models, others may only see theirs results. These permissions are managed by the system administrator. Figure 2 depicts used technologies in the implementation of the modelling platform and their interdependencies.

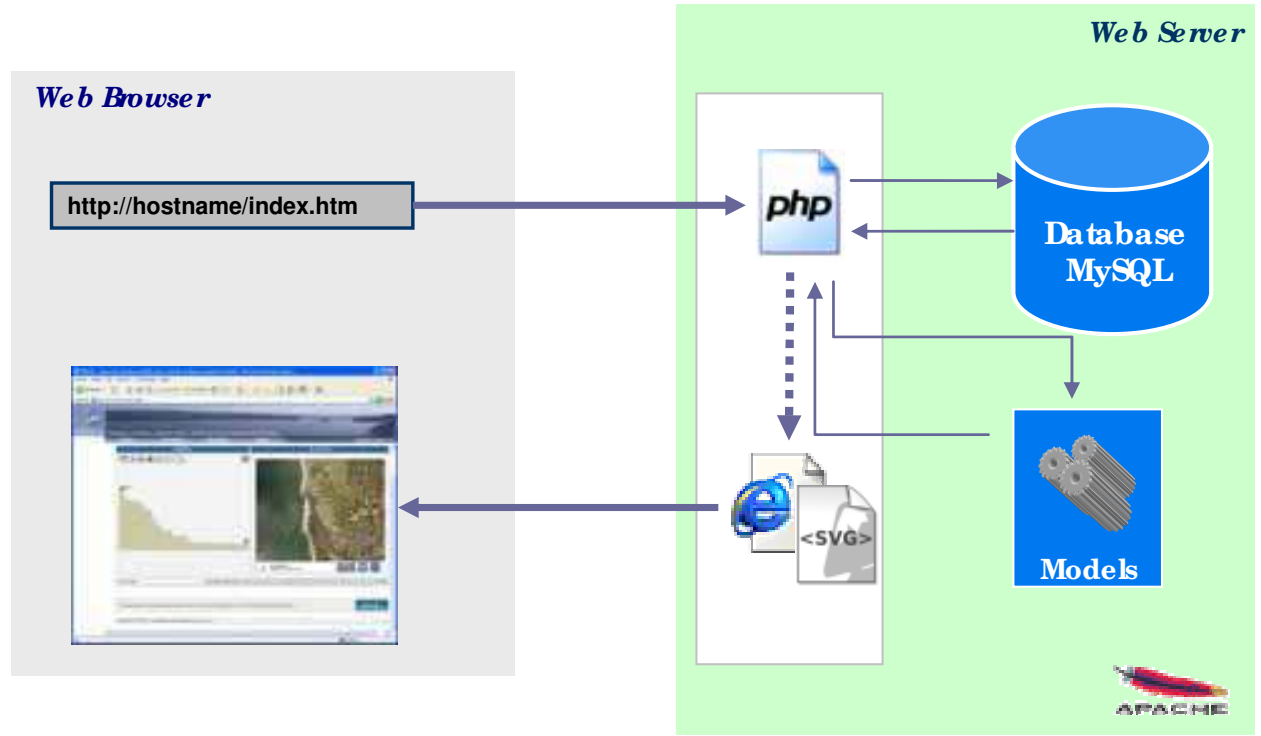

Fig. 2. Adopted technologies for the development of the modelling platform

This system is supported by a web server that provides all the web pages that integrate the interfaces. The basic task of this web server is to receive HTTP requests and to produce HTTP responses, which are mostly HTML documents or other types, such as images, documents, PDF, SVG vector images and simple text. Apache was the selected web server (due to its portability, wide range of services available, and because is a free w eb server).

All the information provided by the web server is stored in a relational database supported by MySQL, the world's most popular open source database server. Besides, MySQL provides many features not available in other systems and is completely free for both commercial and private use. It is a fast and robust system that can handle with unlimited number of users and records. Among the main features of this system are: portability (support for practically any platform); compatibility (there are drivers and interface modules for various programming languages); the excellent performance and stability; user friendly; and requires few resources in terms of hardware.

PHP was adopted as the main programming language (used to generate the HTML pages sent to the clients machines), while the JavaScript language was selected to develop code responsible for the interaction between the user and the interface. The Sobek software is applicable for hydrodynamic and water quality modelling in rivers, and it's composed by 
seven modules: hydrology, hydrodynamics in channels, hydrodynamics in rivers, sewers, real-time control, water quality and floods. Its integrated approach allows the simultaneously simulation of real problems involving different modules. It is based on a robust and reliable numerical method that allows achieving solutions even for highly complex situations.

The consideration of graphical data within the developed interfaces was considered fundamental for a fast and intuitive understanding of the simulated features. In this case, the choice was the image technology SVG (Scalable Vector Graphics). SVG is an XML specification for graphics and has outstanding features as: ability to make enlargements without loss of resolution, the creation of motion graphics that facilitate presentation of results related to dynamic simulations, allows interactivity with the objects represented and the possibility of associating alphanumeric information to graphics. Beyond that, has a reduced download time, compared to other more conventional types of images.

\subsubsection{Information system}

The platform web map server was developed based on the GeoClient application (Rogers and Rosie, 2001). This application has been improved, and some new features and functionalities were added. Noteworthy, was the translation into Portuguese of all the menus and the inclusion of the possibility of automatic export of features to a Google Earth compatible data format. The graphical information themes are organized into databases. Updates of geographical data, adding and deleting data are operations that should be undertaken by the administrator of the database, in accordance with standard methodologies for databases operations. The map visualized in the client side is defined using a form and is automatically generated by an application developed for this purpose. The database administrator can set pre-defined maps. It is also possible for the user to view the results of water quality simulations available on the modelling system. The user must select the rivers and the instant of simulation to be represented in the map interface. The requested map information is communicated to the server and is transferred to the client computer at once. All subsequent operations are dependent on the processing capacity of the client's machine.

The Geoclient application further developed at University of Minho, and integrated in this platform comprises the following major functionalities (Figure 3): full navigation (zoom in, zoom out and pan); map display of alphanumeric data associated to geographic entities; queries with results in chart or table; set labels display properties, export the map to a file, compliant with the Google Earth application; configurable legend presentation; presentation of a navigation map; selection of display options.

Navigation on the map is accomplished through some buttons on the toolbar which allow, for example, zoom in, zoom out and restore the original view. The toolbar shows the cursor coordinates and the labels associated to the graphical entities that are under the cursor. The panning can also be accomplished using the navigation map. The data associated with each graphic object are available, once the information button is pressed. The data are shown on a table and it is possible to generate a chart with the numeric values of all occurrences of the displayed map. The search tool allows the identification of objects throughout a table or a graph/ chart, which satisfy the given search criteria. This criterion can be based on a comprehensive set of comparison operators. Search results can be quickly identified (by zoom in to the object or by its placement in the central area of the map) (Figure 4). 
Web-Based Decision Support Framework for

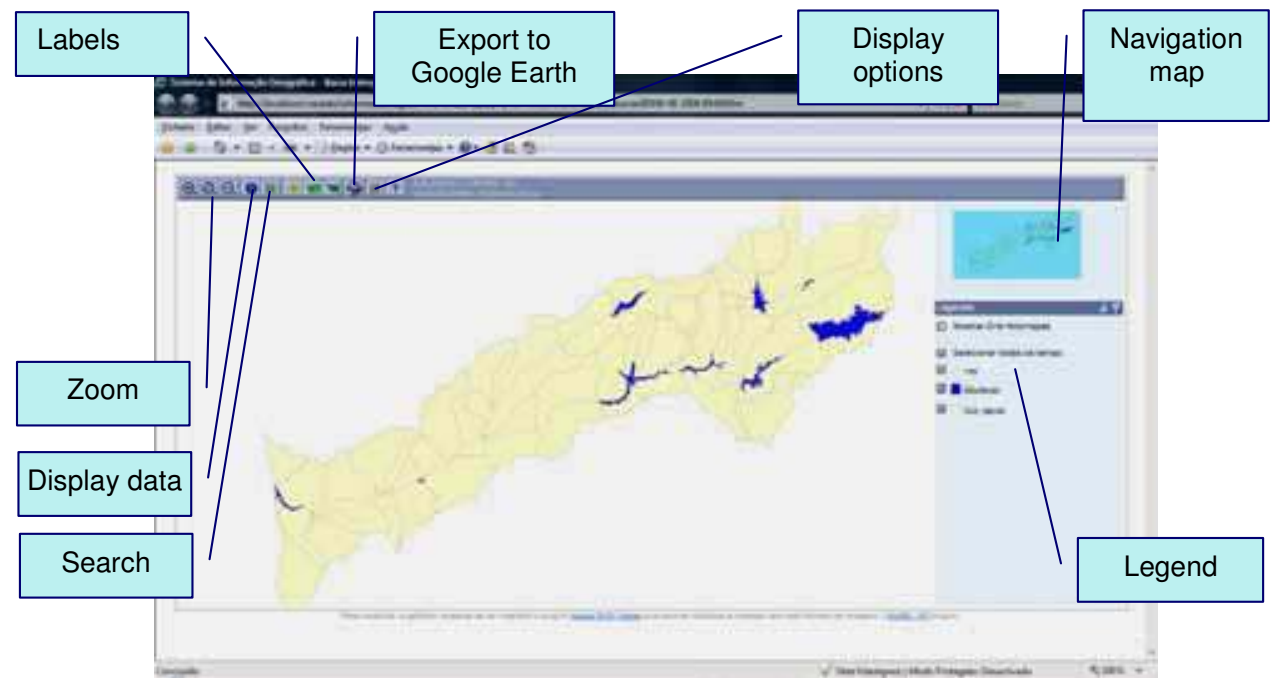

Fig. 3. Web-GIS service for the developed platform

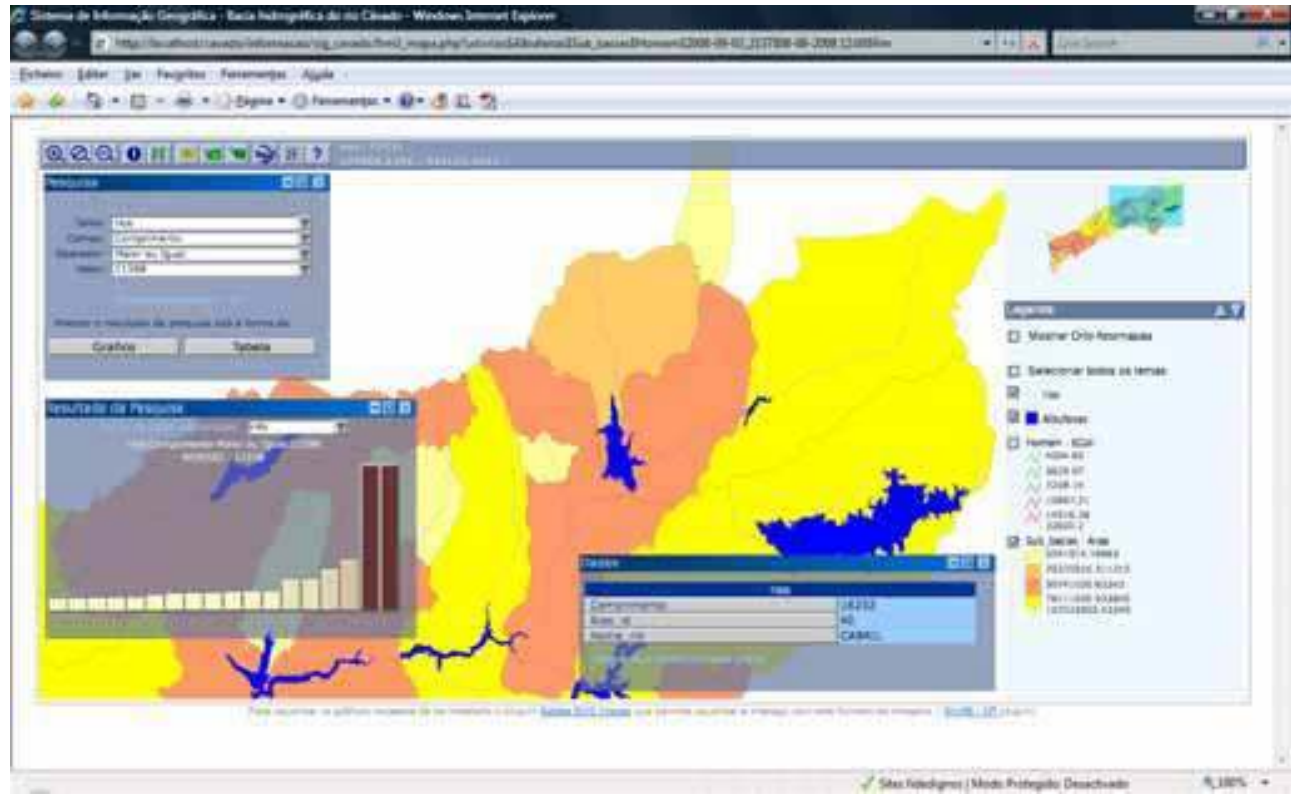

Fig. 4. Search Tool of GeoClient - Web-GIS service application of ODeCav modelling system

Map legend can be customized by the user; it's possible to change the colour of the displayed themes, set their classification according the values of numeric fields and show graphics (bars or circles) for numeric fields. For each object represented on the map there is a field associated on the database that is used for representing their labels on the main view. This feature can be assigned automatically for all entities of the map or placed entity by 
entity. The user has the possibility to define graphical properties of these labels. Finally, the application allows the automatic export of the map for later viewing on the Google Earth application. The export module is designed to convert the different coordinate data used by the two applications (Figure 5).

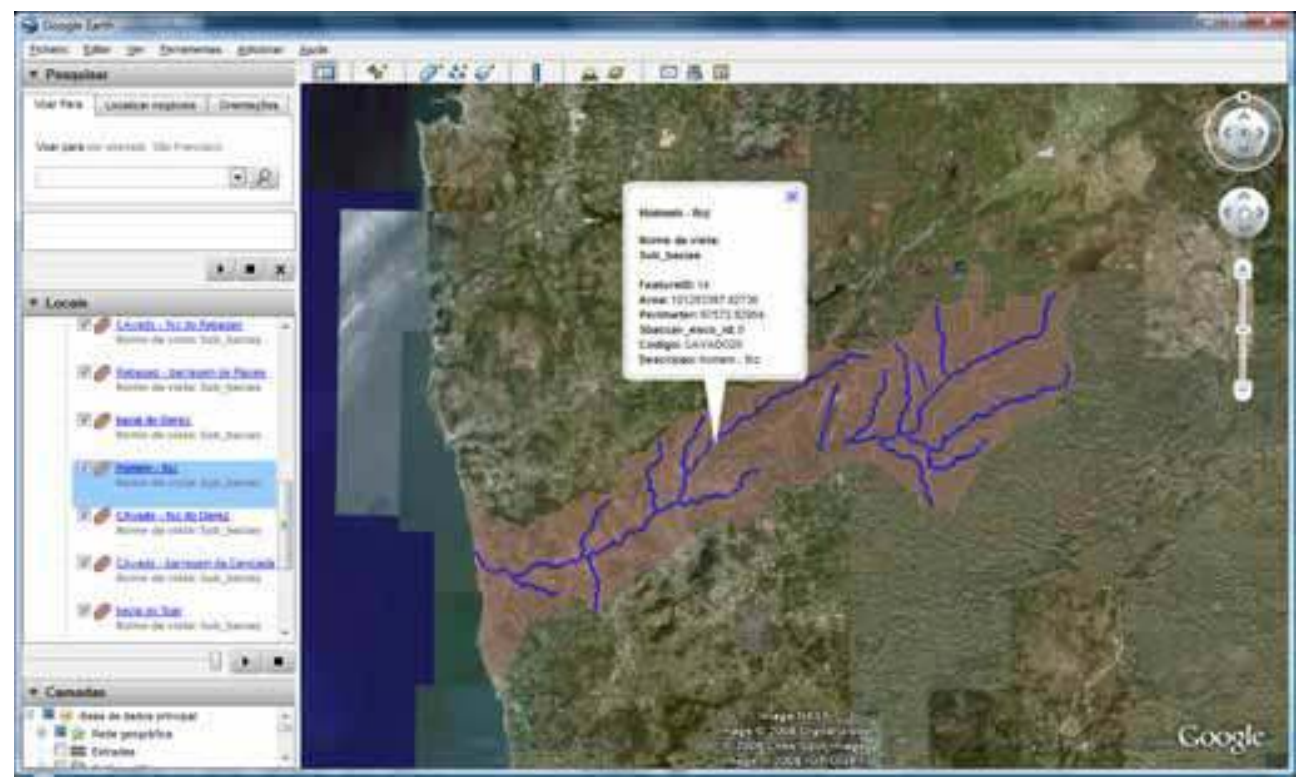

Fig. 5. Export of geographical features to Google Earth compatible data format

In addition it was developed an application to present detailed information about the river network. The application allows making a virtual visit to the rivers, enabling to locate relevant features that are relevant for the rivers hydrodynamics (eg. dams, weirs, controlled gates) and water quality (eg. waste water treatment plants, industries). Navigation is driven by selection of river segments. The user selects the river to visualize from an initial map. Then the navigation tools and the interactive legend allow the user to activate/ deactivate the selected themes.

This application allows the visualization of all the alphanumeric data associated with all the entities and to display photos if available. The information management operations are performed on the database. Operations like insert, update, edition, addition or deleting are performed with proper tools for databases management. Aerial photos are stored outside the database in individual and separated files. Only their basic properties are stored in the database.

Figure 6 presents, for illustrative purposes, some views of river detailed information at river Cávado basin.

Meteorological, hydrometric and water quality information are available on the platform. This database contains historical records of the variables monitored for active monitoring stations. These data are the basis for water quality diagnostics assessment, and to the definition of modelling scenarios to predict the water quality dynamics. 

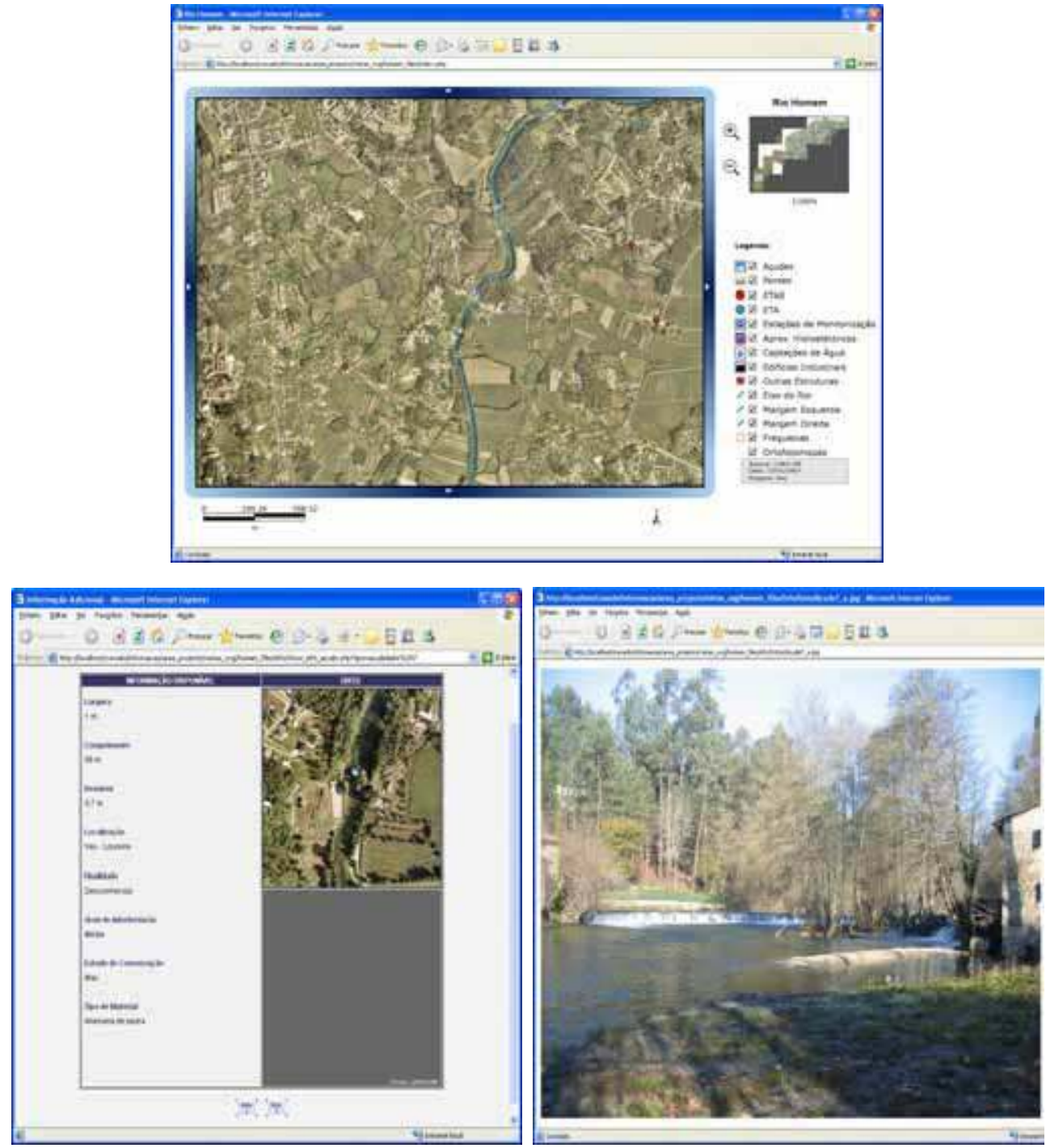

Fig. 6. River detailed information

A web application to access monitoring data was developed. The service provided by this application includes the following functionalities: graphical selection of the monitoring station from the map or from a list of available monitoring stations; graphic visualization of the data series for the selected parameter at a given station, data presentation in tabular layout and the possibility of exporting to a file compatible with MS Excel. It also allows the calculation of statistical parameters of the active data series and the automatic generation of a report. After selection of a particular parameter the associated data is displayed in a graphical layout in the client side (Figure 7). 

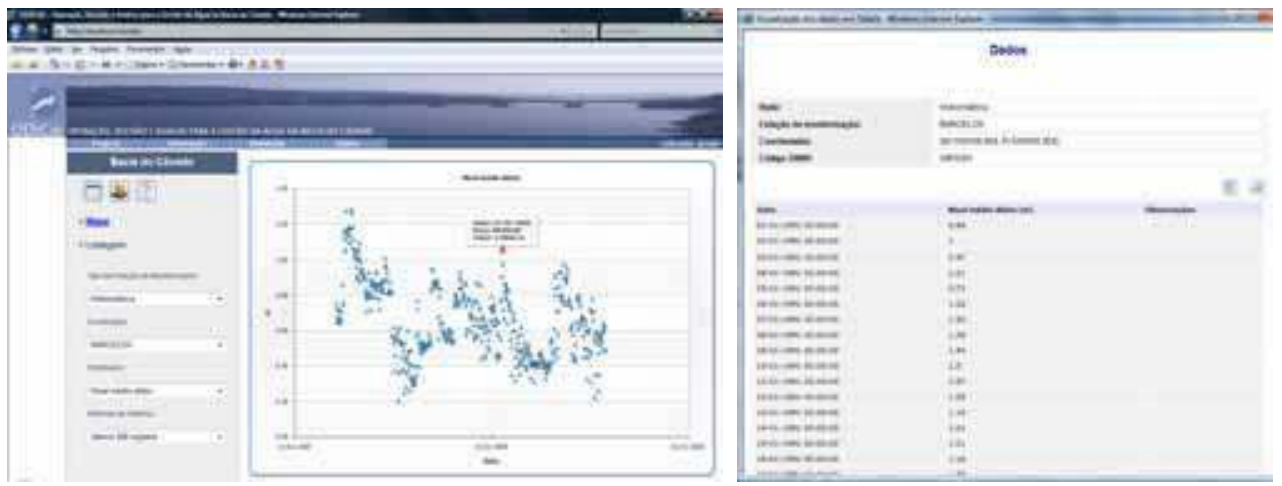

Fig. 7. Monitoring data interface

\subsubsection{Modeling system}

The modelling system consists in mathematical models of the rivers network to simulate river water discharge flows and levels (hydrodynamics) and the transport of substances or properties that are used as water quality indicators.

River Cávado basin is located in the north-western region of Portugal. This basin occupies an area of $1589 \mathrm{~km}^{2}$ and the river network considered in the model is about $360 \mathrm{~km}$ length corresponding to 16 rivers.

Figure 8 depicts the river basin and the modelled river network. The model includes the rivers Cávado and Homem and the following main tributaries: Beredo, Borralha, Cabreira, Cabril, Cavadas, Caveiro, Covo, Febras, Gerês, Milhazes, Pontes, Rabagão, Toco, and Tojal.

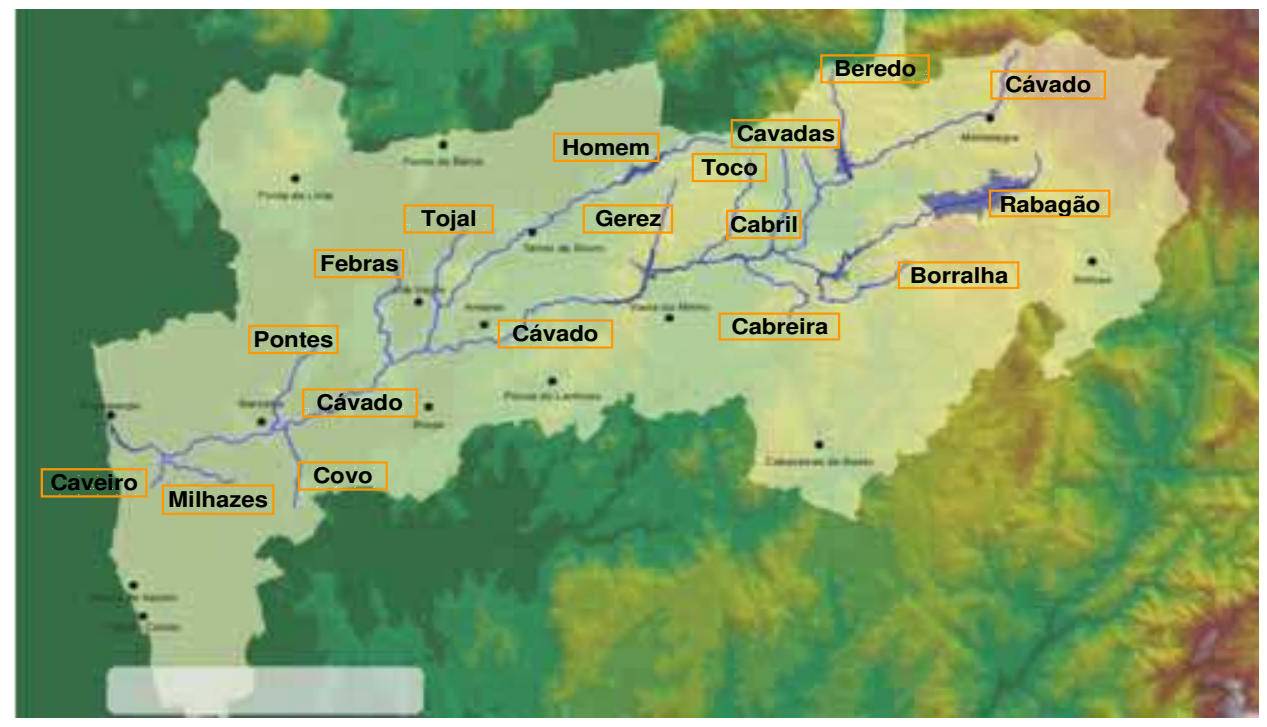

Fig. 8. River Cávado basin and modelled river network 
Cross sections of the river channels considered in the developed model were established using bathymetric and topographic data available for this river basin. The one-dimensional grid comprises 1722 computational nodes, 22 open boundaries, 51 controlled discharges at hydraulic structures and 105 non controlled hydraulic structures. The rivers channels geometry was introduced considering 1854 cross sections. Pollutant sources are simulated considering 84 different locations in the river basin. All hydraulic structures with a significant influence in the rivers flows regime were considered with emphasis for dams and hydropower generation plants.

A web interface to present model results and operate the model execution was developed. This tool interacts with the model installed on a remote server, and allows setting up and activating new simulations. The user has access to applications that permit change the hydraulic structures operational settings during simulations, define hydropower generation time scheduling, establish tributaries discharge flows under different scenarios and define pollutant concentrations and discharges.

Figures 9 and 10 shows the main view of the designed interface for hydrodynamic and water quality models, where several functionalities are available (graphic display of the river profile, plan view, tables and graphics results and animations). This interface allows either setting up the data needed to define new simulations and viewing the results of a selected simulation. The main window of the interface corresponds to the graphical display of the profile (Figure 10).

Each one of the included icons has one or more PHP modules associated responsible to produce the desirable output. As already mentioned, the developed interface allows both setting up the input data for new model simulations and presenting final results. To define

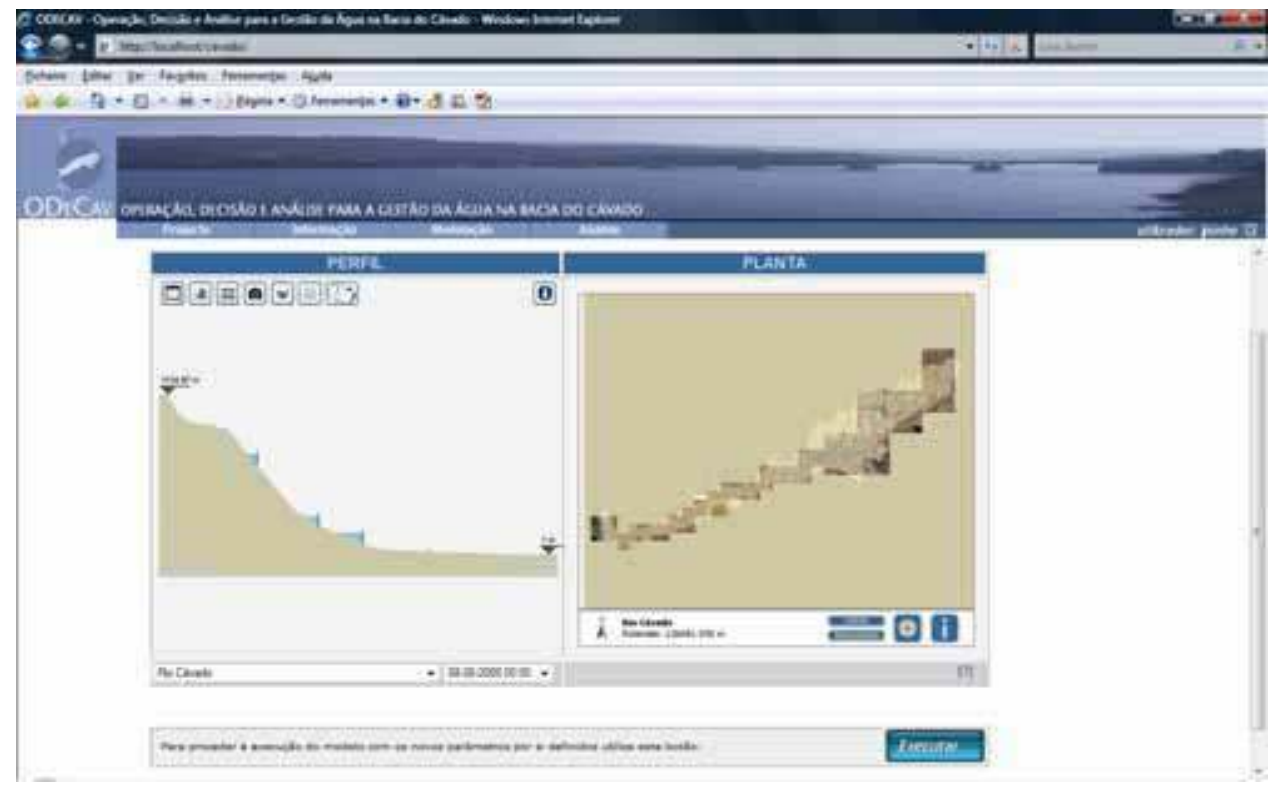

Fig. 9. Web interface for hydrodynamic models 
new simulations an intuitive application was developed as depicted in Figure 11. The user has to follow up the successive forms to define all the data involved in a simulation. New simulations are defined using default data associated with the selected one.

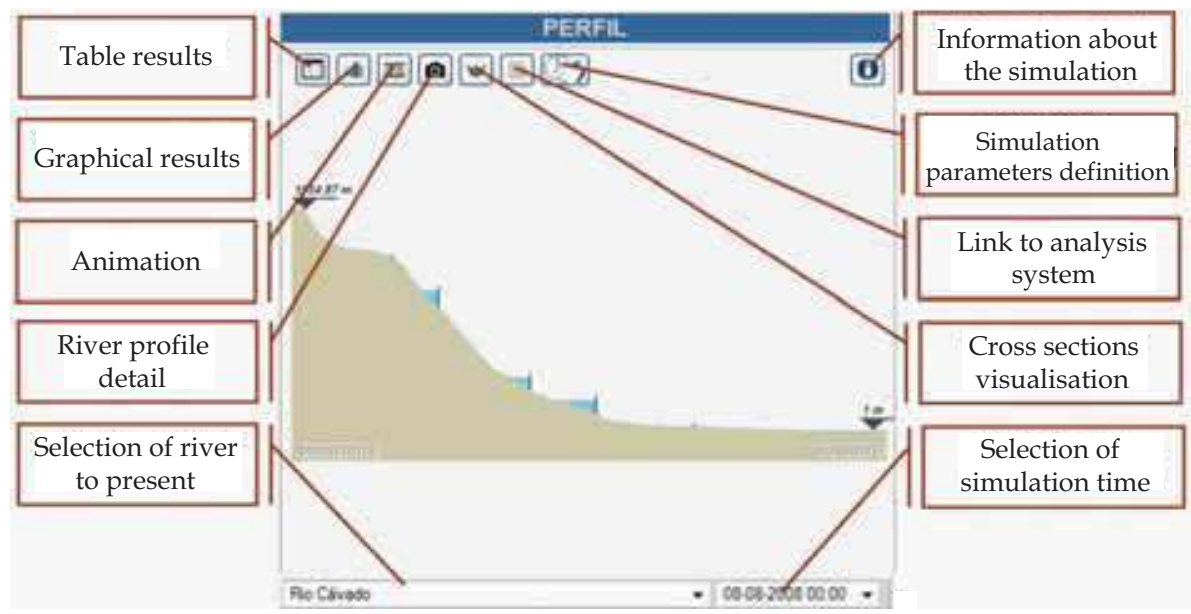

Fig. 10. Main functionalities of the hydrodynamic models web interface: profile view

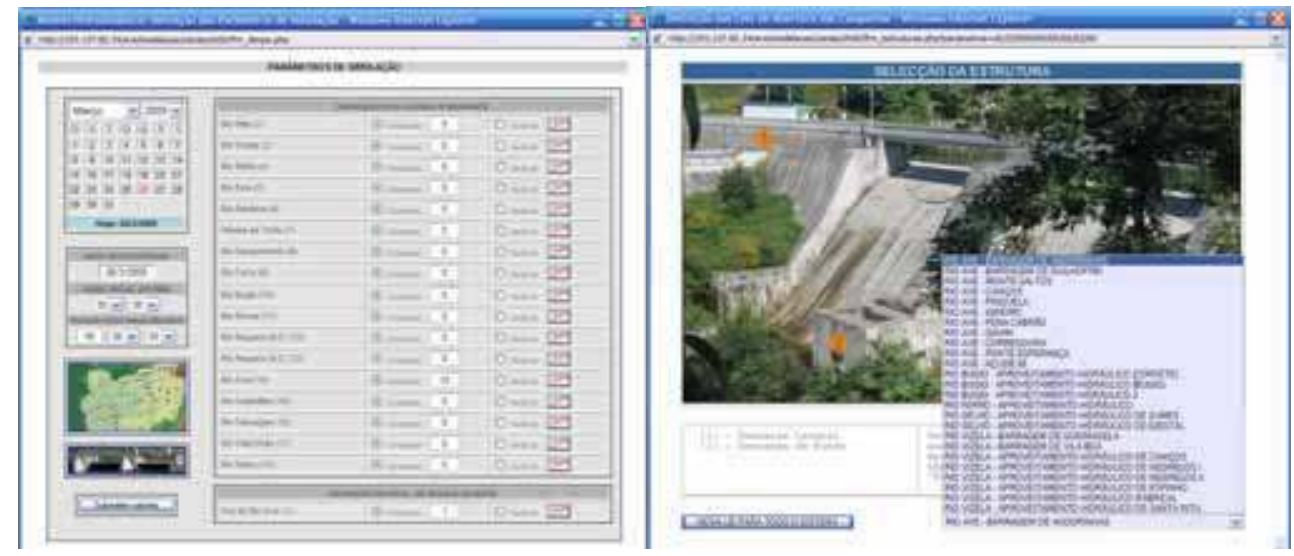

Fig. 11. Main form for definition of new simulations data (left) and interface to define data time series related to hydraulic structures (right)

The script used by this interface is responsible for setting the starting date and duration of the simulations. The presented form allows the definition of the values of river flows at the most upstream open boundaries. It is possible to define a constant value for the entire simulation or a variable law over that period. The image of a dam (as well as images for other hydraulic structures) on the form gives access to a specific new form for setting the opening laws of the gates and orifices (Figure 11 right). Completed the previous steps, the user can execute the model with these new parameters, pressing the "Run" button, located at the bottom of the main window (Figure 9). 


\subsubsection{Analysis system}

The main purpose of this system is to simplify the analysis of complex water systems through presentation of synthesized model results and make available tools for evaluation of different management alternatives. The complexity of environmental systems is related to the uncertainty of the system behaviour caused by lack of essential information to describe natural phenomena and due to the simplifications adopted by mathematical models. This complexity is often intensified by the fact that, there are several actors with shared responsibility in solving the existing problems but usually these actors do not work together.

In the design of the analysis system it was considered the integration of different scales involved in the water resources management problems in a simple and intuitive manner, allowing moving from basin scale to the scale of hydraulic structures within the same application. The analysis of management measures under various environmental scenarios, results in a set of simulations that can be stored by the manager of the developed platform. These stored simulations can be analysed by different users of the modelling system.

Through a specific interface (Figure 12) it is possible to manage (store, consult and remove) different simulations generated in the modelling system. This information is organized by rivers and the analysis is carried out through reports available online. Two separated applications were considered for system analysis: one dedicated to the exploration and analysis of results from hydrodynamic simulations and the second committed to the analysis and exploration of results of water quality. The design and features included in the two interfaces are identical, differing only in the type of results available. This division is justified by the expected use of two distinct groups of users (one group focused on quantitative analysis and the other more interested in qualitative analysis).

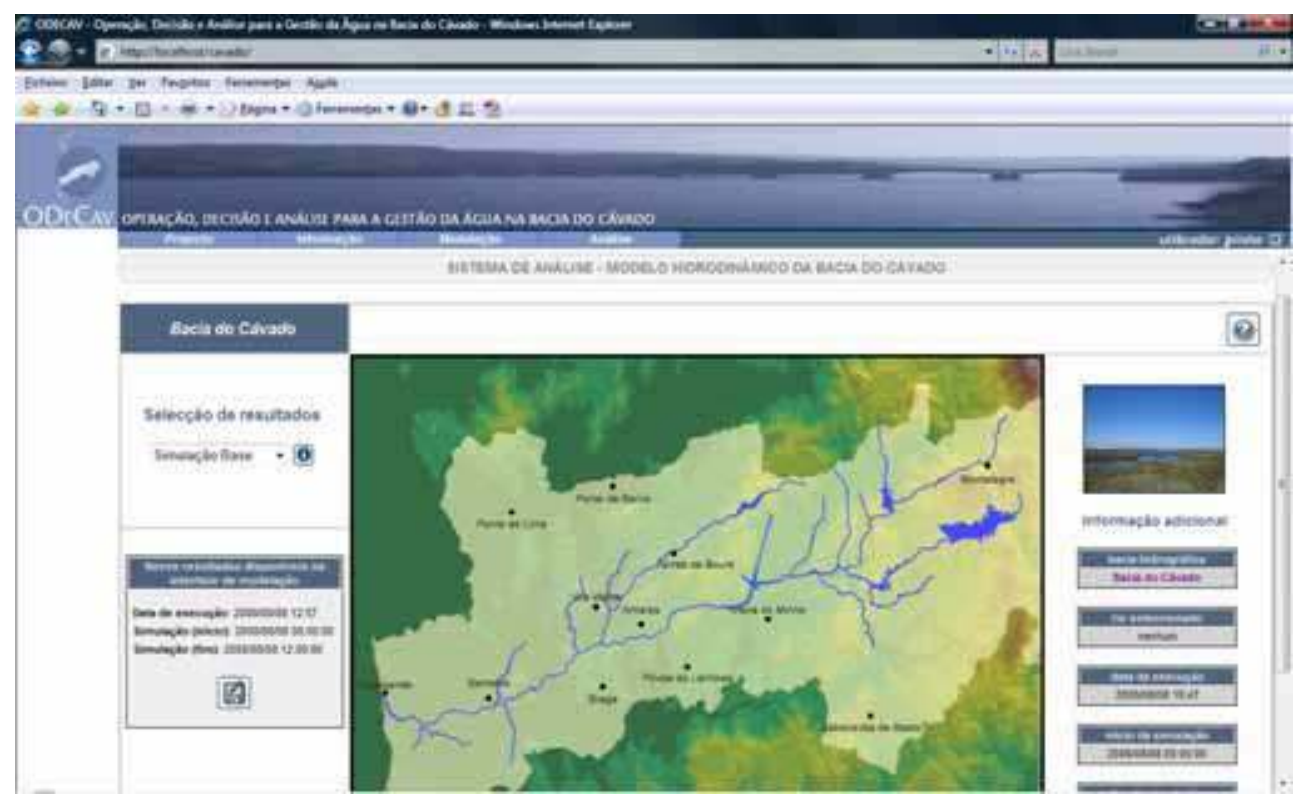

Fig. 12. Main interface of the analysis system 
The main window displays a list box with the available simulations results. It also provides an area with indication of possible simulations available for storage (if the user has permission to store simulations) and an area with additional information about the selected river and simulation data. After selecting the river to be analysed, a plan view of the river is displayed with graphical features that represents river reaches, nodes and hydraulic structures (Figure 13).

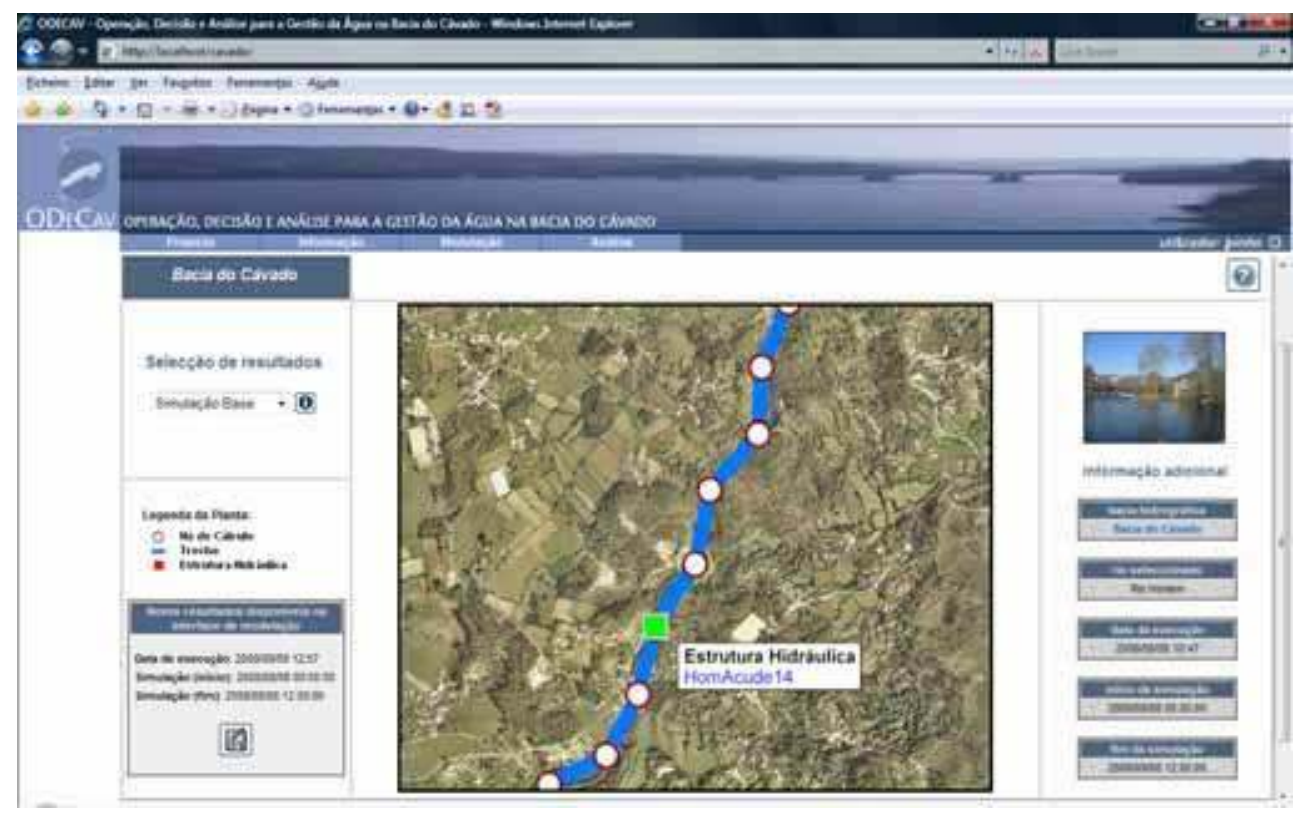

Fig. 13. Plan view for selection of river features in the analysis system

The plan view, also allows visualization of aerial photos, location names and the river name that are used as auxiliary information for easily locate the conceptual elements of the model (nodes, reaches and hydraulic structures). Based on these elements it is possible to automatically generate a report with results of the selected simulation. The report consists of: (i) general information about the simulation and information about the number of model nodes; (ii) reaches or hydraulic structures; (iii) plant and profile location of the selected element; (iv) representation of the profile view at the initial time; (v) intermediate instant and at the final instant of the simulation; (vi) table of results for the active element; (vii) graph of results for all variables associated with the selected element; (viii) and a statistical summary of these variables over the simulation period.

\section{Water quality simulations at the River Cávado Basin}

General procedure for setting up models is briefly presented. In order to illustrate the potentialities of the developed technological platform hydrodynamics and water quality simulations results are presented. Some particular problems of the presented river basin are discussed. 


\subsection{Models implementation}

Models implementation followed a comprehensive procedure that includes four main phases: (i) monitoring data analysis; (ii) identification of key parameters including internal processes parameters or open boundary conditions variables; (iii) model calibration base on monitored data; and (iv) scenarios definition and simulations execution.

All available monitored data was included in the system databases witch facilitate the identification of the relevant hydraulic structures to be included in the model as well as the relevant waste water discharges. The segmentation of the model was defined considering the important influence of the upstream reservoirs in the river flows and the intense occupation (industrial, agriculture and urban areas) of the basin in the downstream areas.

In the calibration procedure a hybrid approach was followed: several parameters were established according to proposed values in the literature (Thomann and Mueller, 1987, Chapra, 1997), from previously developed works about river Cávado water quality (Vieira et al, 1998) and/ or based on available field data.

\subsection{Hydrodynamics}

The hydrodynamic behaviour of the rivers at river Cávado basin is influenced primarily by rainfall regimes in the region and the exploitation of its hydropower facilities. A conceptual framework (Figure 15), where are identified the main structures influencing the hydrodynamic regimes (numbered from 1 to 28) was adopted in order to characterize the data to define the simulation scenarios. For each scenario the rainfall hydrographs and the pumps and turbines operation must be defined.

To illustrate the application of the developed platform thirteen hydrodynamic scenarios were defined in order to estimate average monthly flows and the average flow considering the data included in the information system for the entire available monitoring period.

Turbines were considered fully operational during simulation periods and the water levels at reservoirs are considered near its average level for the month associated with each simulation. It was also considered that other outflow gates at dams are closed. The exceptions were the Venda Nova and Vilarinho das Furnas (Figure 15).

Finally, on the oceanic boundary of the model, no tidal variations were assumed. It was considered that the water level remains at the mean sea level during the simulation period.

All simulations were defined to have duration of 7 days and a computational time step of 15 minutes.

Figure 14 presents a comparison between the estimated (estimation based on monitoring data) and the simulated values at different rivers locations. The presented simulated results refer exclusively to the last instant of the simulation.

From the observation of Figure 14 it is possible to find a close proximity between the estimated and simulated results, with the exception of locations 5, 6 and 12. In the first two locations the difference of $5.6 \mathrm{~m}^{3} / \mathrm{s}$ is due to the introduction of the flow contribution of the sub-basin limited by the Caniçada reservoir and the Febras river at this last location. A similar situation occurs in location 12 . In general, all the other simulations results present a notable approximation to the monitored values. 


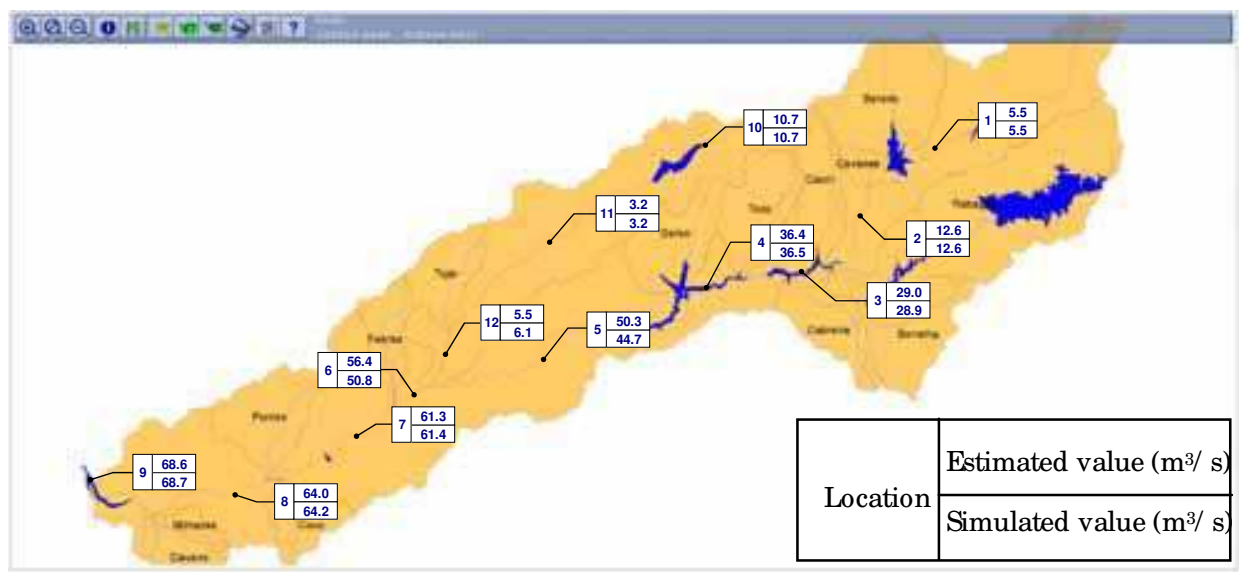

Fig. 14. Estimated average rivers flows and simulated values for a scenario corresponding to the annual mean values of the available monitoring period
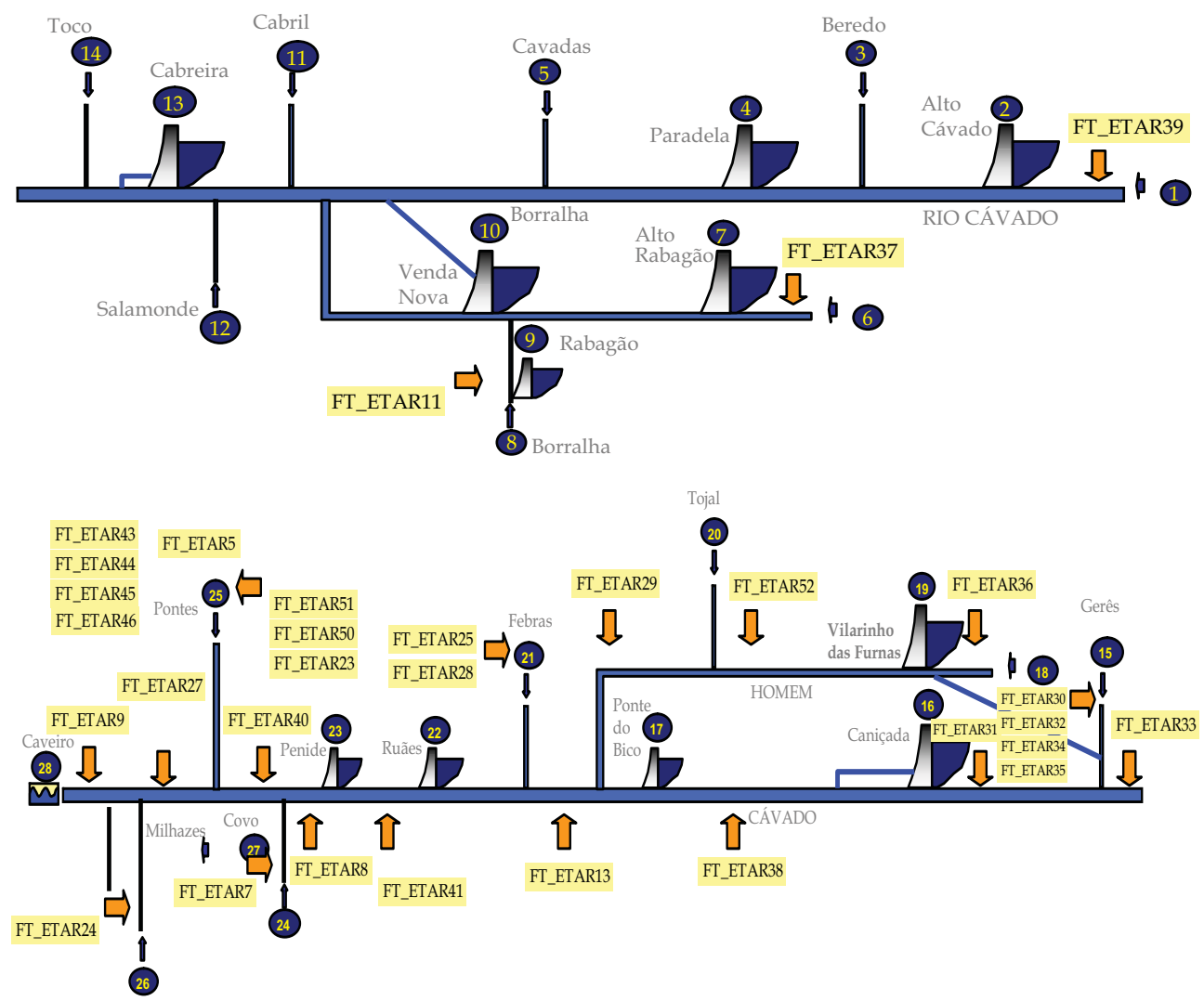

Fig. 15. River Cávado model scheme: WWTP discharges 


\subsection{Water quality}

Simulations of water quality were based on hydrodynamic simulations previously presented and on the consideration of different characteristics for the discharges of waste water treatment plants (WWTP), industries, livestock units, and other contributions associated with different tributaries. The establishment of different values for these pollutant discharges results in different simulation scenarios.

In order to present the potential of the developed modelling system different scenarios were defined for average annual and monthly rivers flows discharges and considering the WWTP efficiency in compliance with their treatment schemes (scenarios 1 to 13). Additionally, for the wettest month (January) and the driest month (August) the effects of discharges from WWTP considering extreme values of its efficiencies were worked out (scenarios 14 to 17). Finally, it was considered three scenarios (scenarios 18 to 20) associated with the failure of each one of the three main WWTP: Frossos, Esposende and Vila Frescaínha (Table 1).

\begin{tabular}{ccc}
\hline Scenario & Hydrodynamics conditions & WWTPefficiencies \\
\hline 1 & Annual & Average \\
2 & January & Average \\
3 & February & Average \\
\hline 4 & March & Average \\
\hline 5 & April & Average \\
\hline 6 & May & Average \\
\hline 7 & June & Average \\
\hline 8 & July & Average \\
\hline 9 & August & Average \\
\hline 10 & September & Average \\
11 & October & Average \\
\hline 12 & November & Average \\
\hline 13 & December & Average \\
14 & January & Maximum \\
15 & August & Maximum \\
16 & January & Minimum \\
17 & August & Minimum \\
18 & Annual & Frossos WWTP failure \\
19 & Annual & Esposende WWTP failure \\
\hline 20 & Annual & \\
\hline & & Vila Fra WWTP failure \\
\hline
\end{tabular}

Table 1. Water quality modelling scenarios 
The qualitative characteristics of the pollutant discharges from WWTP were estimated for the following parameters: biochemical oxygen demand $\left(\mathrm{BOD}_{5}\right)$, dissolved oxygen $(\mathrm{DO})$, and total coliform bacteria (TCB), faecal coliform bacteria (FCB) and streptococci bacteria (SB).

Figure 15 shows the approximate location of all wastewater treatment plant specified in the water quality model.

The loads associated with industrial pollutant discharges were estimated. It was used a simple method based on the industrial activities to compute its waste water discharges. However, most of the industries effluents are treated in WWTP.

Another pollutant sources estimated for each simulation was the livestock farms discharges. The effluent loads were estimated considering the number of heads of cattle per farm.

In the upstream open boundary of the modelled rivers it was considered that the water presents characteristics of unpolluted water, with zero values of concentrations of $\mathrm{BOD}_{5}$ and bacteriological variables. For dissolved oxygen, it was considered a value close to the saturation concentration $(10 \mathrm{mg} / \mathrm{L})$ and a water temperature of $10^{\circ} \mathrm{C}$.

The initial conditions of the model were established by considering the values of average concentrations at the monitoring stations for each water quality variable.

Results were obtained for the twenty scenarios, using a simulation time of seven days for each scenario.

It should be stressed that the results prove to be more sensitive to the values adopted for the concentrations of wastewater discharges than to the calibration coefficients. Once that data series related to those discharges are available it is possible to improve the performance of the water quality model through the fine tune of the calibration coefficients.

Table 2 presents the obtained simulated results for scenario 1 at the last simulation time and the average values monitored at monitoring stations. It appears that for the rivers Homem and Cávado (where monitoring data is available) the water quality profile related with organic matter discharges, inferred from the results of concentrations of $\mathrm{BOD}_{5}$, presents nearly uniform values (around $1 \mathrm{mg} / \mathrm{L}$ ). It was possible to achieve good approximation between the monitored values and model results for this scenario.

The installed treatment capacity of waste water (mainly from domestic sources) in the river basin, based on the removal of organic matter is reflected in the monitored values, resulting in low concentrations of $\mathrm{BOD}_{5}$.

Regarding the results of bacteriological variables the differences between simulated and observed values in scenario 1 , are more significant in the regions located in the most urbanized areas.

The differences between measured and simulated values arise primarily from the uncertainty associated with quantification of bacterial loads (a sensitivity analysis was performed concerning adopted calibration parameters, and it was concluded that these parameters cannot justify the differences found). The values used in the estimation of these loads (mean values of bacterial loads) are highly variable and may justify the simulated behaviour (underestimation of bacterial loads). 

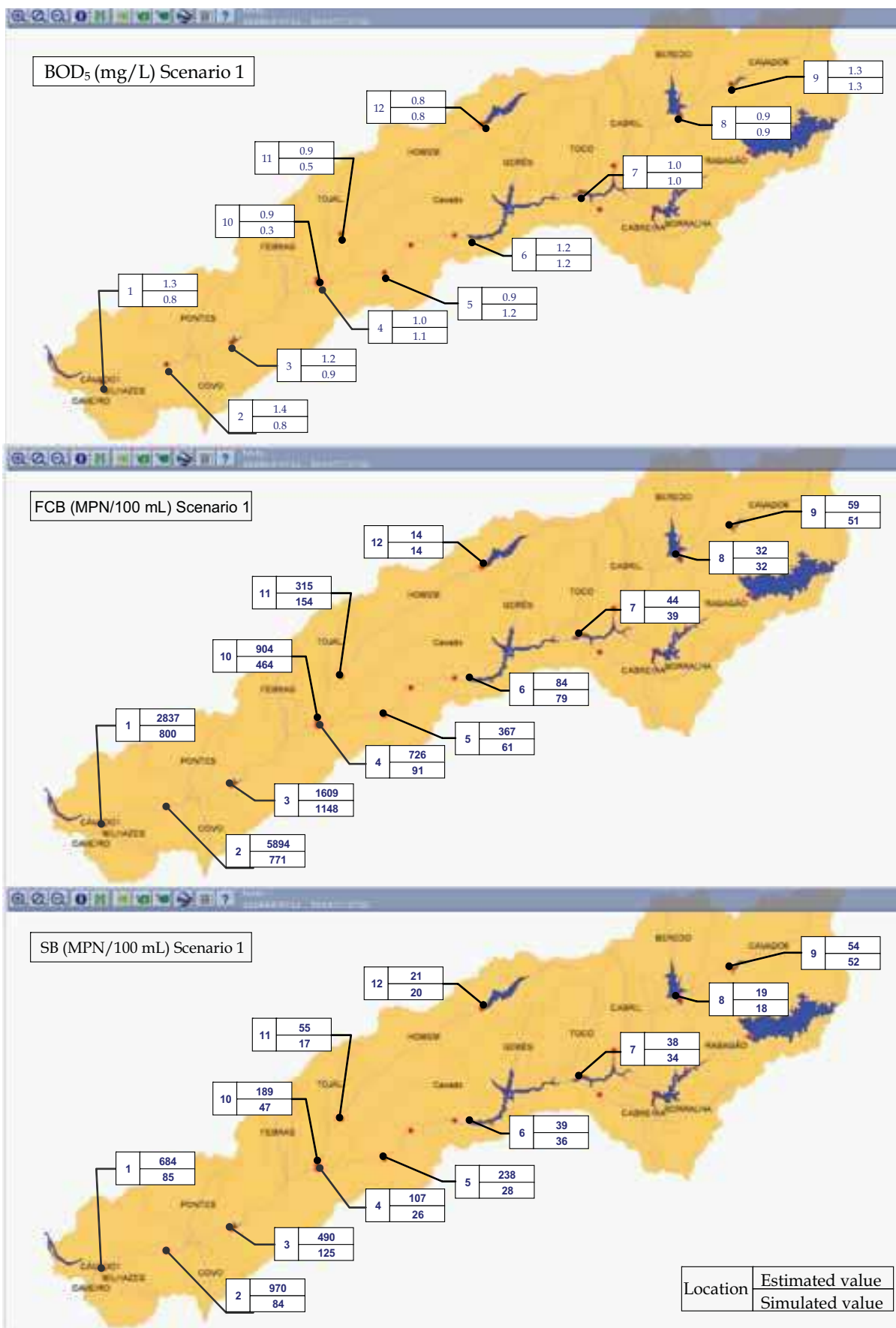

Fig. 16. Water quality model results in the vicinity of monitoring stations for scenario 1 

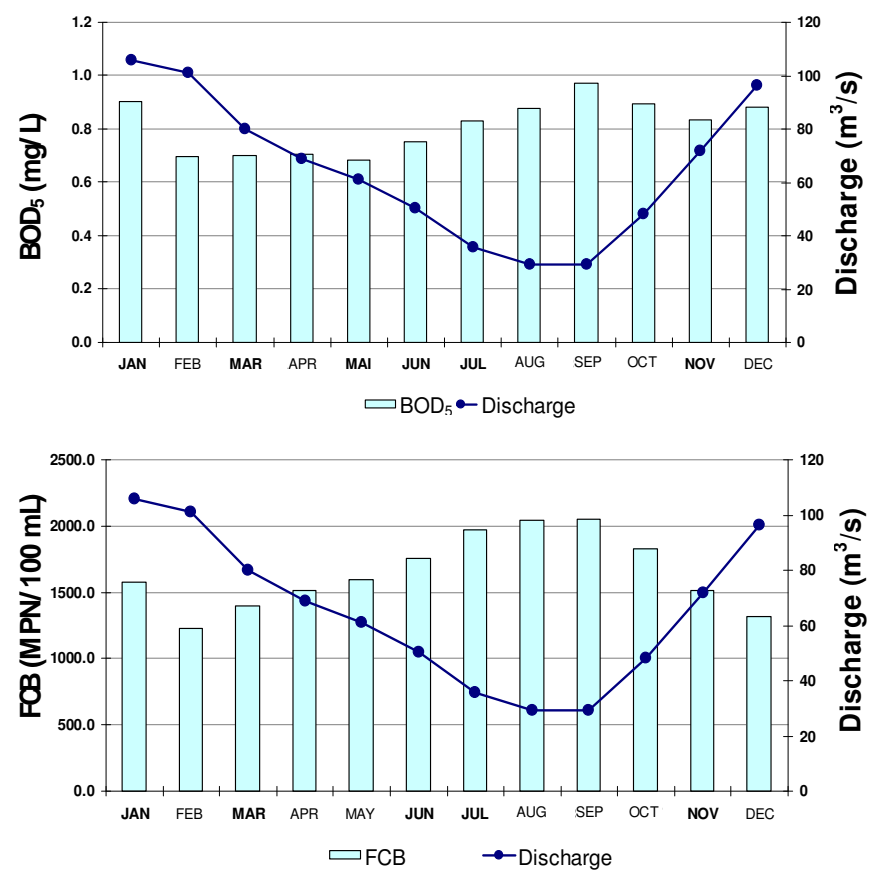

Fig. 17. Concentrations results for $\mathrm{BOD}_{5}$ and $\mathrm{FCB}$ for scenarios 2 to 13 at Ponte Nova de Barcelos in river Cávado
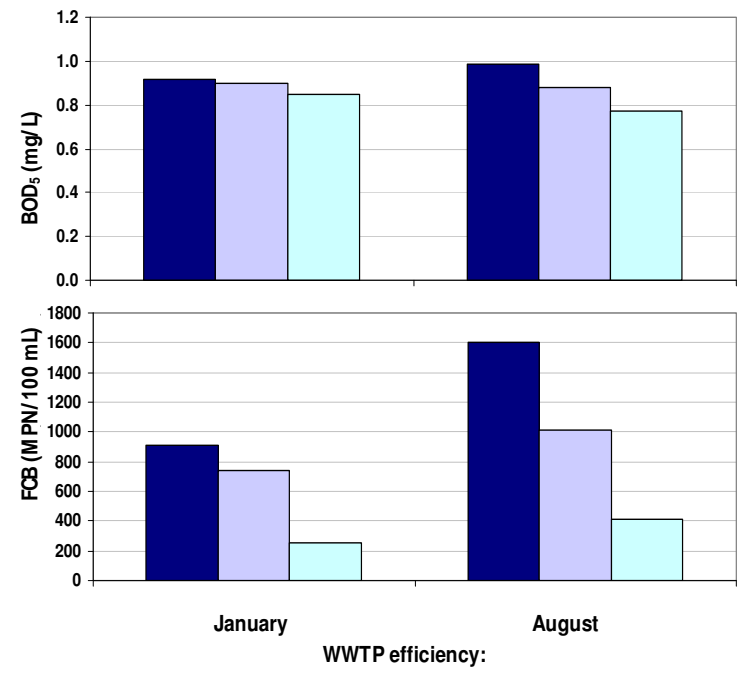

minimum $\square$ average $\square$ maximum

Fig. 18. Concentrations results for $\mathrm{BOD}_{5}$ and $\mathrm{FCB}$ under scenarios 14 to 17 at Ponte Nova Barcelos in river Cávado 
Results for this scenario showed that the bacteriological pollution in the river Cávado stretch downstream the confluence of the river Homem it is a reality that the wastewater treatment solutions have failed to solve in this basin. The bacteriological pollution also occurs during the dry season which decreases the likelihood of contamination come from diffuse sources.

Adopting the same conditions of pollutant discharges of scenario 1 but now considering the average monthly rivers flows discharges, with the simulated scenarios 2 to 13 it is possible to assess the influence of seasonal flow variation on water quality behaviour. Figure 17 shows results in these scenarios in a specific location of the river Cávado: Ponte Nova de Barcelos.

The results reveal a strong influence of the seasonal river flow regime variation on water quality concentrations. The variations reach values of around $70 \%$ of the concentration values in the wettest months in the case of bacteriological variables and about $40 \%$ for $\mathrm{BOD}_{5}$.

Identical results can be achieved with simulations involving different time scales with the ODeCav System. It is particularly interesting to evaluate the influence of hydropower generation plants operational rules on water quality for the rivers Cávado and Homem, since for these two rivers the flow regime is strongly influenced by the operations of those hydraulic structures. Also the influence of hourly variations in flow regimes resulting from energy production on water quality of rivers Cávado and Homem, can be easily assessed once the pollutant discharges in the rivers are known with a similar temporal resolution.

With the scenarios 14 to 17 it is possible to evaluate the impact of different performances of the WWTP assuming different river flow regimes (January and August) in the resultant water quality. Figure 18 depict the obtained results in these scenarios in a location of the river Cávado: Ponte Nova Barcelos.

The results show a greater sensitivity of the river receiving waters to wastew ater discharges in the dry season, for all simulated variables.

Although the efficiencies of the WWTP considered in each of the scenarios have been defined from literature values, there is a great variability in the resulting receiving waters concentrations, especially for bacteriological variables. For the presented location, the concentrations of bacterial variables when treatment plants operate with a minimum efficiency it is approximately four times the concentration when treatment plants operate at maximum efficiency. The developed modelling system reveal to be very important for the evaluation of alternative wastewater treatment investments since it allows, in a simple way, to anticipate the effects of these structures to improve water quality in river receiving waters.

Finally, it is presented in Figure 19 results for the Frossos WWTP rupture scenario (scenario 18). The rupture is simulated for a situation of average runoff and therefore not reflect the worst situation in terms of impact on water quality.

The presented results refer to two distinct locations: one in the vicinity of the discharge (immediately downstream) of the WWTP and the other on a stretch away. Based on this kind of results protective measures can be planned and the affected water uses can be anticipated, minimizing the impact of this potential accidental situation. 


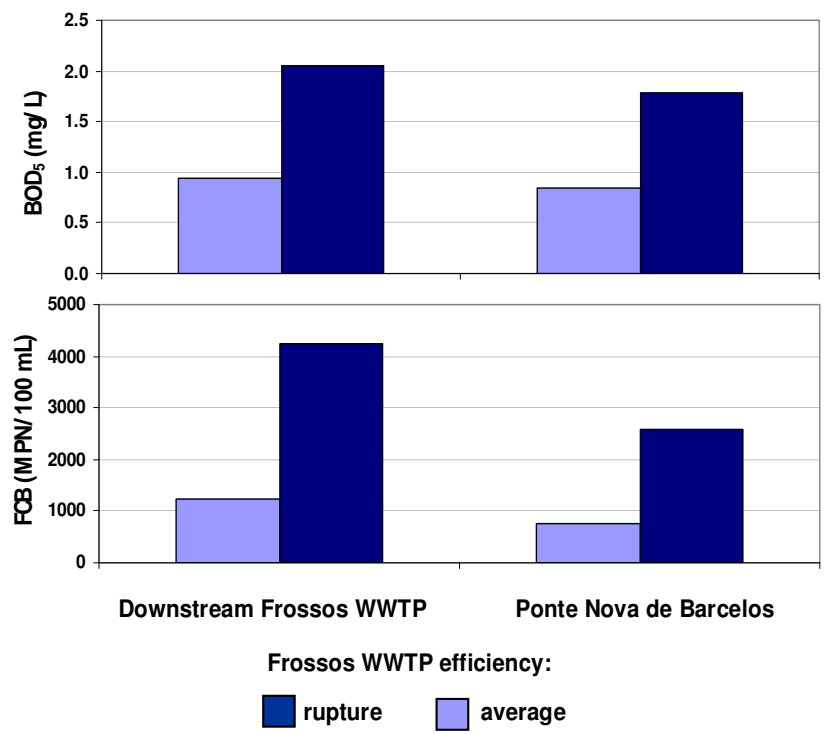

Fig. 19. Concentrations results of $\mathrm{BOD}_{5}$ and $\mathrm{FCB}$ for the scenario 18 (rupture of Frossos WWTP) at two different locations

It should be noted that the results presented in this chapter are not exhaustive. All simulations are made available with the installation of ODeCav System and can be found on the web based platform.

The presented examples illustrate the potential of the developed system for management of water quality at river Cávado basin.

\section{Conclusions}

The developed operational modelling platform allows the simulation of an unlimited number of scenarios. Several scenarios were implemented in order to evaluate its performance after a judicious effort for model calibration and validation.

Main obtained results for the rivers within the basin reveal an almost uniform longitudinal profile for BOD concentration with a good agreement between observed and simulated results. The installed wastewater treatment capacity in the watershed (domestic and industrial wastewater) is reflected in the observed values leading to low concentrations of BOD. However, a quite different situation is observed for bacteriological indicators. In the lower part of the basin, concentrations results for all simulated scenarios are always lower than the observed ones even in the dry season. The reason for this fact can be the existence of untreated discharges or the lack of disinfection in WWTP.

The presented decision support tool for the river Cávado basin constitutes a robust and efficient technological platform to support water management at a river basin scale. Obtained results allow predicting that this new tool will be extremely effective and important to achieve the objectives of water management at river basin scale. In the next 
years, the use of all the potentialities of this kind of platforms in practical situations under different water management problems constitutes a major challenge for its evaluation. Moreover, water authorities once decide to use this kind of management tools will certainly see improved their analysis capabilities, strengthening their technological skills for the adoption of more sustainable water management policies. Especially it is adequate for developing big projects since it facilitates collaborative studies in one common platform and the modelling results became much more transparent for all project partners.

\section{Acknowledgment}

The authors thank to Comissão de Coordenação e Desenvolvimento Regional do Norte, Águas do Ave, SA and Águas do Cávado, SA, for the financial support.

\section{References}

Berlekamp, J., Lautenbach, S., Graf, N., Reimer, S. \& Matthies, M. 2007 Integration of MONERIS and GREAT-ER in the decision-support system for the Elbe river basin. Environ Model Softw22(2):239-247.

Borowski, I. \& Hare, M. 2007 Exploring the gap between water managers and researchers. Difficulties of model-based tools to support practical water management. Water Resources Management 21 (7), 1049-1074.

Chapra, S. 1997. Surface water-quality modeling. The McGraw-Hill Companies, Inc.

De Kok, J. L., Kofalk, S., Berlekamp, J., Hahn, B. M. \& Wind H. 2008 From Design to Application of a Decision-support System for Integrated River-basin Management, Water Resources Management, (23), 1781-1811.

DELTARES 2009 SOBEK software. Available from:< http:/ / delftsoftw are.wldelft.nl/ >.

Dudley, J., Daniels, W., Gijsbers, P. J. A., Fortune, D., Westen, S. \& Gregersen, J. B. 2005 Applying the Open Modelling Interface (OpenMI), Proceedings of the MODSIM 2005 conference, Melbourne, Australia.

European Commission 2000 Directive of the European Parliament and of the Council 2000/60/ EC Establishing a Framework for Community Action in the Field of Water Policy, Official Journal 2000 L 327/ 1, European Commission, Brussels.

Horn, A., Rueda, F.J., Hörmann, G. \& Fohrer, N. 2004 Implementing river water quality modelling issues in mesoscale watershed models for water policy demands - an overview on current concepts, deficits, and future tasks. Physics and Chemistry of the Earth 29, 725-737.

MYSQL 2009 MySQL database server. Available from:<http:/ / www.mysql.com/ >.

Price, R. K. 2000 Hydroinformatics and urban drainage: an agenda for the beginning of the 21st century, Journal of Hydroinformatics, vol. 2, No. 2, 133-147.

Ravesteijn, W. \& Kroesen O. 2007 Tensions in water management; Dutch tradition and European policy. Water Science and Technology 56(4): 105-111.

Rekolainen, S., Kämäri J. \& Hiltunen M. 2004 A conceptual framework for identifying the need and role of models in the implementation of the Water Framework Directive. International Journal of River Basin Management 1(4):1-6.

Thomann R. V., and J. A. Mueller. 1987. Principles of Surface Water Quality Modeling and Control. Harper and Row, Inc., New York. 
Vieira, J. M. P., Pinho, J. L. S., and Duarte, A. 1998. Eutrophication vulnerability analysis: a case study. Water Science and Technology, 37(3), 121-128.

Volk, M., Hirschfeld, J., Dehnhardt, A., Schmidt, G., Bohn, C., Liersch, S. \& Gassman, P.W. 2008 Integrated ecological-economic modelling ofwater pollution abatement management options in the Upper Ems river basin. Ecological Economics Special Issue Integrated Hydro-Economic Modelling 66, 66-76. 


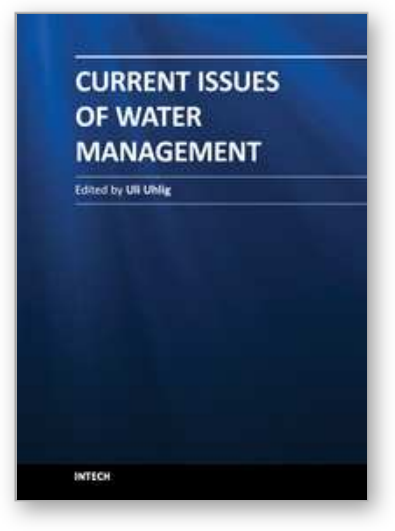

\author{
Current Issues of Water Management \\ Edited by Dr. Uli Unlig
}

ISBN 978-953-307-413-9

Hard cover, 340 pages

Publisher InTech

Published online 02, December, 2011

Published in print edition December, 2011

There is an estimated 1.4 billion $\mathrm{km} 3$ of water in the world but only approximately three percent (39 million $\mathrm{km} 3$ ) of it is available as fresh water. Moreover, most of this fresh water is found as ice in the arctic regions, deep groundwater or atmospheric water. Since water is the source of life and essential for all life on the planet, the use of this resource is a highly important issue. "Water management" is the general term used to describe all the activities that manage the optimum use of the world's water resources. However, only a few percent of the fresh water available can be subjected to water management. It is still an enormous amount, but what's unique about water is that unlike other resources, it is irreplaceable. This book provides a general overview of various topics within water management from all over the world. The topics range from politics, current models for water resource management of rivers and reservoirs to issues related to agriculture. Water quality problems, the development of water demand and water pricing are also addressed. The collection of contributions from outstanding scientists and experts provides detailed information about different topics and gives a general overview of the current issues in water management. The book covers a wide range of current issues, reflecting on current problems and demonstrating the complexity of water management.

\title{
How to reference
}

In order to correctly reference this scholarly work, feel free to copy and paste the following:

José Pinho, José Vieira, Rui Pinho and José Araújo (2011). Web-Based Decision Support Framework for Water Resources Management at River Basin Scale, Current Issues of Water Management, Dr. Uli Uhlig (Ed.), ISBN: 978-953-307-413-9, InTech, Available from: http://www.intechopen.com/books/current-issues-of-watermanagement/web-based-decision-support-framework-for-water-resources-management-at-river-basin-scale

\section{INTECH}

open science / open minds

\section{InTech Europe}

University Campus STeP Ri

Slavka Krautzeka 83/A

51000 Rijeka, Croatia

Phone: +385 (51) 770447

Fax: +385 (51) 686166

www.intechopen.com

\section{InTech China}

Unit 405, Office Block, Hotel Equatorial Shanghai

No.65, Yan An Road (West), Shanghai, 200040, China 中国上海市延安西路65号上海国际贵都大饭店办公楼 405 单元

Phone: +86-21-62489820

Fax: $+86-21-62489821$ 
(C) 2011 The Author(s). Licensee IntechOpen. This is an open access article distributed under the terms of the Creative Commons Attribution 3.0 License, which permits unrestricted use, distribution, and reproduction in any medium, provided the original work is properly cited. 